\title{
Comida de rua: avaliação das condições higiênico-sanitárias de manipuladores de alimentos
}

\author{
Street food: analysis of hygienic and sanitary conditions \\ of food handlers
}

Giovanna Carbonera de Souza ${ }^{1}$

Celso Tadeu Barbosa dos Santos ${ }^{2}$

Anderson Assunção Andrade ${ }^{2}$

Luciene Alves ${ }^{1}$

${ }^{1}$ Departamento de Nutrição, Instituto de Ciências da Saúde, Universidade Federal do Triângulo Mineiro (UFTM). Praça Manoel Terra 330, Abadia. 38025015 Uberaba MG Brasil. anderson@icbn.uftm.edu.br ${ }^{2}$ Departamento de Microbiologia, Imunologia e Parasitologia, Instituto de Ciências Biológicas e Naturais, UFTM.

\begin{abstract}
The consumption of street food is an economical and practical alternative for the population. However, concerns regarding the safety of these foods are increasing. Thus, this study aimed to analyze the hygienic and sanitary conditions of the street food trade in Uberaba in the State of Minas Gerais. For this purpose, 30 street vending sites were evaluated using a structured questionnaire and microbiological analysis of food handlers' hands and food contact recipients and surfaces. The findings showed low adequacy of street food regarding hand hygiene and food contact surfaces. With respect to surfaces, the results for mesophilic aerobic microorganisms revealed that only $23.3 \%$ had satisfactory sanitary conditions. The level of contamination of hands by fecal thermotolerant coliforms and/or Coagulase positive Staphylococci was unsatisfactory in approximately $47 \%$ of food handlers. The conclusion drawn is that the hygienic and sanitary conditions of food handlers in Uberaba are poor. It is therefore necessary to adopt effective and permanent training programs on food safety for food handlers urgently. Key words Street food, Food handler, Street vendors, Food safety, Microbiological analysis
\end{abstract}

Resumo O consumo de alimentos de rua é uma alternativa econômica e prática para a população. No entanto, as preocupações sobre a segurança destes alimentos são cada vez maiores. Assim, este estudo teve como objetivo analisar as condições higiênico-sanitárias do comércio ambulante de alimentos em Uberaba-MG. Para isso, além da aplicação de um questionário em 30 pontos de comércio ambulante, foram realizadas também análises microbiológicas nas mãos dos manipuladores e nas superfícies dos recipientes que acondicionam os alimentos. Os achados mostraram baixa adequação dos ambulantes em relação às condições de higiene de mãos e superfícies em contato com os alimentos. Nas superfícies, os resultados para microrganismos aeróbios mesófilos mostraram que apenas 23,3\% apresentavam condições satisfatórias de limpeza. O nível de contaminação das mãos por coliformes termotolerantes e/ou Staphylococcus coagulase positiva foi insatisfatório em aproximadamente $47 \%$ dos manipuladores. Conclui-se que as condições higiênico-sanitárias de vendedores ambulantes de alimentos em Uberaba são deficientes. Portanto, é urgentemente necessária a adoção de programas eficazes e permanentes de treinamento em segurança alimentar para os manipuladores de alimentos.

Palavras-chave Comida de rua, Manipulador de alimentos, Vendedores ambulantes, Segurança alimentar, Análise microbiológica 


\section{Introdução}

A comercialização de alimentos nas ruas por vendedores ambulantes é comum em muitas cidades de países em desenvolvimento e constitui uma alternativa econômica, prática e flexível de alimentação para a população em geral ${ }^{1,2}$. Os vendedores ambulantes estão estrategicamente situados em rotas de alto tráfego de pedestres, como estações de ônibus e trens, calçadas em pontos de táxi, áreas próximas a instalações industriais, hospitais, escolas e universidades ${ }^{3,4}$.

Particularmente em relação às cidades onde existem muitos estudantes universitários, como é o caso de Uberaba, MG, há uma grande demanda pelas refeições nas ruas próximas às universidades, em função do estilo de vida destes estudantes, que valorizam uma alimentação de sabor agradável, mas que ao mesmo tempo possa ser consumida rapidamente, e seja de baixo custo ${ }^{5,6}$.

Muitas pessoas consomem diariamente refeições nas ruas, e estudos revelam que o número de vendedores de alimentos nesses locais continua aumentando, pois muitos comerciantes enxergam esta atividade como um bom negócio, o qual fornece boa fonte de renda e requer baixo investimento de capital ${ }^{3,4,7}$.

O negócio de venda de alimentos nas ruas representa uma fonte de renda alternativa e tem contribuído de modo expressivo para a redução da pobreza em muitos países em desenvolvimento ${ }^{3,7}$. No entanto, há relatos significativos de problemas à saúde associados ao aumento do consumo desses alimentos ${ }^{7,8}$.

Fatores como a infraestrutura local precária, as características dos produtos comercializados e a falta de atuação do serviço de Vigilância Sanitária, aumentam as preocupações sobre a segurança dos alimentos vendidos nas ruas ${ }^{7}$. Estes fatores, associados a outros como ignorância dos vendedores ambulantes em relação às boas práticas de manipulação, baixa qualidade da matéria-prima, manutenção da comida em temperaturas inadequadas de conservação e falta de proteção efetiva dos alimentos contra insetos e poeira, aumentam o risco de transmissão de doenças de origem microbiana veiculadas por alimentos ${ }^{2-4}$.

Embora muitos casos dessas doenças transmitidas por alimentos tenham sido atribuídos ao cozimento incorreto, à manutenção de temperaturas inadequadas e à utilização de matérias-primas contaminadas; a má higienização das mãos e das superfícies que interagem com os alimentos também são identificadas como fatores de risco importantes ${ }^{9,10}$.
Muitos estudos indicam que algumas bactérias, após o contato inicial, sobrevivem nas mãos e superfícies por horas ou até mesmo dias. Assim, visando garantir a segurança alimentar, é fundamental que as mãos sejam adequadamente lavadas e as superfícies sanitizadas. A eficácia destes processos é frequentemente avaliada por meio da detecção de microrganismos indicadores ${ }^{9-13}$.

Microrganismo indicador é um microrganismo ou um grupo de microrganismos cuja detecção é sugestiva da presença de agentes patogênicos. Os microrganismos indicadores associados às práticas de higiene incluem, entre outros, aeróbios mesófilos, coliformes termossensíveis e termotolerantes, e Staphylococcus coagulase positiva $(\mathrm{SCP})^{9}$.

Assim, o objetivo deste estudo foi avaliar as condições higiênico sanitárias do comércio ambulante de alimentos em Uberaba, por meio da determinação de bactérias indicadoras nas mãos dos manipuladores e nas superfícies de contato com os alimentos. Além disso, buscou-se verificar o nível de conhecimento e as atitudes dos vendedores ambulantes em relação à segurança alimentar e às práticas de higiene.

\section{Métodos}

Foram avaliados 30 pontos de comércio ambulante de alimentos, situados na cidade de Uberaba-MG.

Visto que se trata de comércio informal sem registro de seu quantitativo total no município, optou-se por uma amostra não probabilística. Porém a escolha dos estabelecimentos foi realizada de forma aleatória e estratificada. Considerando que este tipo de comércio geralmente localiza-se em regiões de grande fluxo de pessoas, foi utilizado como critério o mapeamento do município em diferentes áreas como a região central, as proximidades de hospitais, de universidades e de escolas. Estes locais foram visitados e por sorteio foi feito o convite a, no mínimo, 20\% dos estabelecimentos em cada local para participarem da pesquisa.

A proposta apresentada foi de uma pesquisa quantitativa, descritiva e transversal, com estudos de análises microbiológicas das mãos dos manipuladores e das superfícies dos recipientes que acondicionam os alimentos a serem vendidos. Além disso, foi aplicado um questionário de avaliação das condições higiênico-sanitárias dos estabelecimentos.

A coleta das amostras e a aplicação do questionário foram realizadas simultaneamente pela 
mesma pessoa, entre Novembro de 2012 e Janeiro de 2013, de segunda a sexta-feira durante o período noturno (das 19:00h às 22:00h), sem notificação prévia da data ou hora da pesquisa.

Os procedimentos tiveram início após a autorização dos proprietários para a realização do estudo, mediante a assinatura do Termo de Consentimento Livre e Esclarecido (TCLE).

A pesquisa foi aprovada pelo Comitê de Ética em Pesquisa da Universidade Federal do Triangulo Mineiro (CEP - UFTM).

A Vigilância Sanitária Municipal de Uberaba-MG relata não ter conhecimento sobre o quantitativo total de vendedores ambulantes. $\mathrm{O}$ Departamento de Posturas Municipais é o órgão responsável por fiscalizar os comerciantes de alimentos nas ruas e exigir o cumprimento das normas estabelecidas pela RDC 216/2004, que dispõe sobre o Regulamento Técnico de Boas Práticas para Serviços de Alimentação ${ }^{14}$.

\section{Avaliação das condições \\ higiênico-sanitárias}

Com o intuito de avaliar as Boas Práticas de Fabricação (BPF) no comércio de ambulantes, foi aplicado um questionário (Quadro 1) composto por 43 itens de verificação abrangendo os seguintes tópicos: Perfil do Ambulante $(n=7)$; Higiene Pessoal do Ambulante [Vestuário $(\mathrm{n}=6)$, Práticas Higiênicas $(n=6)]$, Estado de Saúde $(n=$ 4), Programa de capacitação dos manipuladores e supervisão $(n=4)$; Higienização de utensílios, equipamentos e carrinhos para a manipulação de alimentos $(\mathrm{n}=10)$; Manipulação de alimentos ( $\mathrm{n}$ =4) e Manejo de resíduos $(\mathrm{n}=2)$.

\section{Coleta das amostras}

As coletas das amostras foram feitas pela técnica do esfregaço de superfície com swabs estéreis, de acordo com as recomendações da American Public Health Association (APHA) ${ }^{15}$, com pequenas modificações. Para a coleta de amostras das superfícies de contato com os alimentos, um $s w a b$ umedecido em água peptonada $0,1 \%$ (H2Op) foi aplicado em área de $50 \mathrm{~cm}^{2}$ delimitada por um molde estéril. O swab foi friccionado nesta área por três vezes, com movimentos giratórios e formando um ângulo de $45^{\circ}$ com a superfície, descrevendo movimentos da direita para a esquerda e depois de baixo para cima. Para a coleta de microrganismos das mãos dos manipuladores, um swab umedecido em H2Op foi aplicado na mão direita de cada manipulador, da seguinte forma: partindo da região dos punhos, o swab foi passado com movimentos giratórios da parte inferior da palma até a extremidade dos dedos e voltando ao punho. Esse movimento foi repetido três vezes na direção de cada dedo. Depois, realizou-se o procedimento nas bordas da mão, entre os dedos e embaixo das unhas.

Após a coleta das amostras de mãos e superfícies, os swabs foram dispensados em tubos de ensaio identificados, com tampa de rosca contendo $10 \mathrm{ml}$ de $\mathrm{H}_{2} \mathrm{Op}$. Esses tubos foram imediatamente colocados sob refrigeração e transportados até o Laboratório de Microbiologia da UFTM, para as análises microbiológicas serem realizadas.

\section{Análises microbiológicas}

Com as amostras coletadas das mãos dos manipuladores procederam-se as contagens de SCP, coliformes termossensíveis e termotolerantes. Já nas amostras coletadas das superfícies de contato com os alimentos foram determinadas as contagens de microrganismos aeróbios mesófilos. Todas as análises foram feitas conforme recomendações da $\mathrm{APHA}^{15}$.

Para a análise de microrganismos aeróbios mesófilos foram feitas diluições decimais seriadas das amostras $\left(10^{-1} \mathrm{a} 10^{-3}\right)$ e alíquotas de $0,1 \mathrm{ml}$ foram semeadas em Ágar Padrão para contagem (PCA). As placas foram incubadas a $37^{\circ} \mathrm{C}$ por 48 horas. Após, as colônias foram contadas e o resultado foi expresso em Unidades Formadoras de Colônias (UFC) por $\mathrm{cm}^{2}$ de superfície.

Para a contagem de SCP, 0,1 ml das amostras preparadas como anteriormente descrito, foi semeado na superfície do Ágar Baird-Parker $(\mathrm{BP})^{16}$. Em seguida à incubação a $37^{\circ} \mathrm{C}$ por 48 horas, as colônias que se apresentaram suspeitas foram submetidas à coloração de gram e aos testes de produção de coagulase e de catalase. Como controle positivo foi utilizada a linhagem $S$. aureus ATCC 29213. Os resultados foram expressos como UFC/mão.

As contagens de coliformes termossensíveis e termotolerantes foram determinadas pelo método do Número Mais Provável (NMP) ${ }^{17}$. Brevemente, $1 \mathrm{ml}$ da amostra e de cada uma de suas duas diluições decimais seriadas $\left(10^{-1}\right.$ a $\left.10^{-2}\right)$ foi inoculado em três tubos contendo Caldo Lauril Sulfato Triptose (LST), os quais foram incubados a $35^{\circ} \mathrm{C}$ por 24 a 48 horas (teste presuntivo para coliformes termossensíveis). A confirmação da presença de coliformes termossensíveis foi realizada a partir da semeadura de amostras dos tubos positivos de LST (com formação de gás) em tubos com Caldo Bile Verde Brilhante 2\% (BVB), seguida pela incubação a $35^{\circ} \mathrm{C}$ por 24 a 48 ho- 
Quadro 1. Questionário de Avaliação de Boas Práticas de Fabricação no comércio ambulante de alimentos.

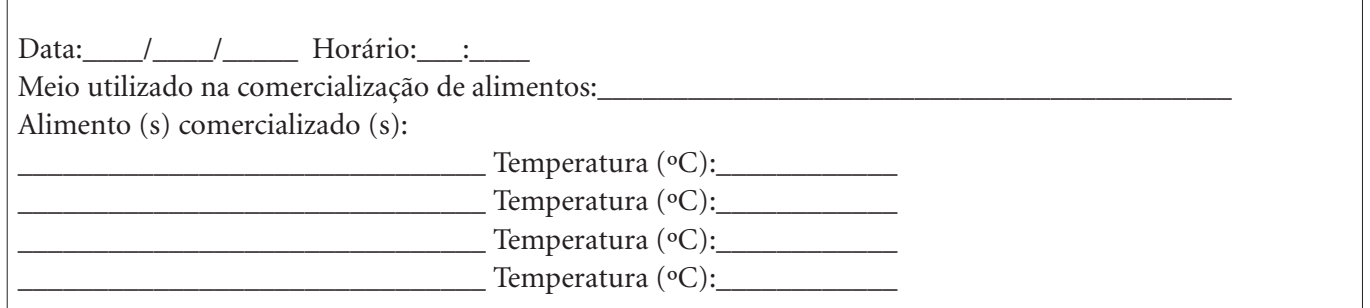

\section{1- Perfil do Ambulante}

Idade:___anos Sexo: ( ) M ( )F

Escolaridade: ( )Analf. ( ) $1^{\circ} \mathrm{a} 4^{\mathrm{o}}$ do Fund.

( ) Médio incompleto ( ) Médio completo ( )Superior incompleto ( ) Superior completo Horário de trabalho:__ Dias: ( )2f ( )3f ( )4f ( )5f ( )6f ( )Sáb ( )Dom

Opção pelo comércio ambulante: ( )Possibilidade de melhor rendimento

( ) Identificação com o trabalho ( ) Falta de qualificação para outra atividade

( ) Outros:

Trabalho como principal atividade ( )SIM ( )NÃO, principal

\section{2- Higiene Pessoal do Ambulante}

\subsection{Vestuário}

Utiliza uniforme (jaleco branco) fechado, limpo e em bom estado de conservação Utiliza adornos

Boa apresentação pessoal

Mãos limpas, unhas curtas, sem esmalte

Cabelos protegidos com touca ou rede

Contato das mãos com os alimentos (uso de luvas corretamente ou pegadores)

2.2 Práticas Higiênicas

Hábito de lavar a mão antes de manipular alimentos

Manipula dinheiro entre as manipulações com alimentos

O que utiliza para lavar as mãos: ( )água ( )detergente ( )sabonete ( )outros:

Local de lavagem das mãos: ( )reservatório com água ( )no próprio estabelecimento

( )outros:

Modo de secagem das mãos: ( )pano ( )toalha de papel ( )outros:

Local das necessidades fisiológicas: ( )banheiro de estabelecimento comercial

( )outros:

\subsection{Estado de Saúde}

Ausência de afecções cutâneas e feridas; ausência de sintomas de infecções

respiratórias, gastrointestinais e oculares

Em caso de ferimento, cuida e protege adequadamente o local ferido

Realiza periodicamente exames de rotina (sangue, fezes, urina).

Frequência:

Trabalha quando fica doente (por ex. gripe, infecção de garganta, diarreia)

2.4 Programa de capacitação dos manipuladores e supervisão

Existe programa de capacitação relacionado à manipulação de alimentos

Existe supervisão das condições higiênico- sanitárias.

Em caso afirmativo, frequência:

Em caso de irregularidades, o fiscal: ( )aplica multa ( )orienta sobre como corrigir a irregularidade

ras. Alíquotas dos tubos positivos de BVB foram semeadas em Caldo Escherichia coli (EC) e incubadas a $45^{\circ} \mathrm{C}$ por 24 horas para a confirmação da presença de coliformes termotolerantes. Os resultados foram expressos em NMP de coliformes termossensíveis ou termotolerantes por mão. 
Quadro 1. continuação

3- Higienização de utensílios, equipamentos e carrinhos para a manipulação de alimentos.

\subsection{Utensílios}

Material resistente à corrosão, tamanho e forma que permitem fácil higienização

Adequado estado de conservação e número suficiente para o tipo de operação realizada

Armazenados em local apropriado e de forma organizada

3.2 Equipamentos

Superfícies em contato com os alimentos: lisas, íntegras, impermeáveis, resistentes

a corrosão e de fácil higienização

Termômetro nos locais de conservação

Equipamento para conservação pelo calor e frio

3.3 Higienização de equipamentos e utensílios

Produtos utilizados na higienização: ( )álcool ( )água ( )detergente ( )sabão

( )outros:

Utensílios utilizados na higienização: ( )pano ( )esponja de aço ( )esponja ( )escova

3.4 Carrinhos

São guardados em área limpa, livre de objetos em desuso, livre de poeiras, de acúmulo de lixo, de água estagnada

Produtos utilizados na higienização: ( )álcool ( )água ( )detergente ( )sabão

( )outros:

\section{4- Manipulação de alimentos}

\section{Manipulação de alimentos}

Molhos e temperos em sachês

Gelo produzido com água potável

Produtos embalados, identificados e armazenados à temperatura adequada.

Como são transportadas:

( )carro ( )ônibus ( )a pé ( )outros:

( )temperatura ambiente ( )caixas térmicas ( )outros:

\section{5- Manejo de resíduos}

\section{5- Manejo de resíduos}

Recipientes para coleta de resíduos

Recipientes com acionamento não manual

‘NA: Não se aplica

\section{Resultados e discussão}

\section{Avaliação das condições \\ higiênico-sanitárias}

Em relação às características dos vendedores ambulantes incluídos neste estudo, os dados revelaram que a maioria $(60 \%-18 / 30)$ era do sexo masculino, a idade variou de 22 a 69 anos, e a média de idade foi de 44 anos. Dados similares foram encontrados em Nairobi, no Quênia, onde $60 \%$ dos vendedores de alimentos na rua $(48 / 80)$ também pertenciam ao gênero masculino ${ }^{18}$.

Mais da metade dos alimentos comercializados $(56,6 \%$ - 17/30) pertencia à categoria de lanches e cachorros quentes. Os demais $(43,4 \%$ - 13/30) compreendiam uma variedade de produtos, incluindo pastéis, salgados, macarrão, pipoca, churros e algodão doce.

Os resultados apresentados na Tabela 1 correspondem à higiene pessoal dos manipuladores. Estes apontam baixo índice de cuidados pessoais, sobretudo no item referente a mãos limpas, unhas curtas e limpas, sem esmalte $(43,3 \%$ de adequação); e no item ausência de utilização de adornos (46,7\% de adequação).

As mãos são as principais fontes de transmissão de microrganismos aos alimentos. De acordo com a Portaria RDC n ${ }^{\circ} 216$ de 15 de Setembro de $2004^{14}$, os manipuladores de alimentos devem 
Tabela 1. Análise da adequação da higiene pessoal dos vendedores ambulantes de alimentos em UberabaMG, entre Novembro de 2012 e Janeiro de 2013.

\begin{tabular}{lcc}
\hline \multicolumn{1}{c}{ Itens avaliados } & $\begin{array}{c}\text { Número de } \\
\text { Ocorrência } \\
(\mathbf{n = 3 0 )}\end{array}$ & \% \\
\hline Uniforme (jaleco branco) limpo e & 16 & 53,3 \\
em bom estado de conservação. & & \\
Ausência de utilização de adornos. & 14 & 46,7 \\
Boa apresentação pessoal. & 25 & 83,3 \\
Mãos limpas, unhas curtas e & 13 & 43,3 \\
limpas, sem esmalte. & & \\
$\begin{array}{l}\text { Cabelos protegidos com touca ou } \\
\text { rede. }\end{array}$ & 18 & 60,0 \\
\end{tabular}

estar com as mãos limpas após uma correta higienização; as unhas devem estar curtas, sem esmalte ou base, e durante a manipulação com alimentos devem ser retirados todos os objetos de adorno pessoal, além da maquiagem. Um estudo realizado na cidade de Uberlândia - MG, com 10 ambulantes, constatou também alto índice de desconformidade em relação ao asseio corporal dos ambulantes $(80 \%)$, considerando itens como mãos com esmalte, presença de adornos, entre outros ${ }^{19}$.

Especificamente em relação à presença de adornos, um estudo sobre as condições de higiene praticadas por 63 vendedores ambulantes de alimentos na cidade de Owerri, Nigéria, revelou o uso de adornos em 19,05\% da amostra ${ }^{20}$. No presente estudo encontramos um desacordo ainda maior (53,3\%). O uso de adornos por parte de manipuladores de alimentos é uma falha grave, pois permite o acúmulo de sujidades e de microrganismos, aumentando o risco potencial de contaminação das mãos e transmissão dos microrganismos aos alimentos.

Ainda em relação aos itens para avaliar a adequação da manipulação dos alimentos, 53,3\% (16/30) dos ambulantes relataram ter o hábito de lavar as mãos antes de manipular os alimentos; observou-se que 46,7\% (14/30) têm contato direto das mãos com alimentos e 53,3\% (16/30) manipulam dinheiro e alimentos simultaneamente.

A questão da higienização adequada das mãos tem sido destacada em vários trabalhos, sendo que esta prática deve ser realizada antes da manipulação dos alimentos, bem como após qualquer interrupção do processo de manipulação. A ausência de lavagem das mãos no ato da comercialização dos alimentos e a manipulação destes e de dinheiro pelo mesmo comerciante propiciam uma elevação dos níveis de contaminação das mãos e, consequentemente, dos produtos alimentícios disponíveis para venda, caso haja contato entre eles ${ }^{20-22}$. Em uma pesquisa em dez pontos de venda de alimentos de rua na cidade de Uberlândia, MG, constatou-se que em todos os casos o dinheiro e o alimento eram manipulados pela mesma pessoa ${ }^{19}$.

Durante a lavagem das mãos, 33,3\% (10/30) dos ambulantes declararam fazê-la somente com água, em detrimento da utilização de água e detergente ou água e álcool, citados por $60 \%$ $(18 / 30)$ e $6,7 \%(2 / 30)$ dos ambulantes, respectivamente. Nenhum dos participantes da pesquisa relatou fazer o processo de antissepsia das mãos corretamente, com sabonete antisséptico, água e álcool em gel 70\%, recomendado pela Associação Brasileira de Refeições Coletivas (ABERC) ${ }^{23}$, o que contribui com o aumento de riscos de transmissão de agentes patogênicos nos alimentos comercializados. Obteve-se predomínio de relatos de secagem das mãos com pano, compreendendo 70\% (21/30) dos comerciantes.

Em relação à disponibilidade de local para realização das necessidades fisiológicas, apenas 26,7\% (8/30) dos ambulantes alegaram possuir banheiro anexo ao estabelecimento comercial. Os demais 73,3\% (22/30) relataram utilizar banheiros próximos ao local de trabalho, como o de igrejas, residências, universidade, hospital ou de outros estabelecimentos comerciais.

Em relação à saúde do manipulador, 40\% (12/30) dos ambulantes relataram trabalhar quando adoecem por gripe, infecção de garganta ou diarreia. Em relação à periodicidade da realização de exames de rotina (sangue, fezes e urina), $56,7 \%(17 / 30)$ dos vendedores afirmaram fazê -los anualmente.

Campos et al. ${ }^{21}$, ao avaliarem as práticas de higiene realizadas por manipuladores de alimentos de escolas municipais de Natal-RN, detectaram $51,9 \%$ de inadequação no que se refere ao monitoramento anual do estado de saúde. A $\mathrm{ABERC}^{23}$ ressalta que não é permitida a manipulação de alimentos por pessoas que apresentem distúrbios gastrointestinais e infecções pulmonares ou orofaríngeas, ainda que estes problemas de saúde estejam inaparentes.

Em relação aos recipientes para manejo de resíduos, 13,3\% dos estabelecimentos (4/30) eram desprovidos dos mesmos. Sobre serem tampados e com acionamento não manual (pedal), dos 26 estabelecimentos que continham recipientes, apenas 30,8\% (8/26) seguia com acionamento não manual. $\mathrm{O}$ acionamento manual da tampa 
de recipientes para manejo de resíduos certamente contribui para o aumento dos níveis de contaminação das mãos.

A observação das características dos utensílios e superfícies utilizados na manipulação de alimentos revelou que apenas 46,7\% (14/30) apresentavam material resistente à corrosão, além de tamanho e forma que permitiam fácil higienização. A maioria dos ambulantes $(80 \%-24 / 30)$ higienizava os utensílios e equipamentos apenas com água e detergente, 10\% (3/30) com água e álcool, e 10\% com água, detergente e álcool 70\%.

Os dados claramente revelam falta de cuidados com a higienização correta das superfícies dos recipientes que acondicionam os alimentos. A ABERC ${ }^{23}$ recomenda que esta higienização seja realizada de acordo com os procedimentos convencionais de limpeza para a não proliferação de microrganismos, ou seja, com água corrente, detergente neutro e posterior desinfecção com solução clorada 200 partes por milhão (ppm) ou álcool 70\%.

Outra inconformidade observada com frequência foi a utilização de panos (60\% - 18/30) no processo de limpeza das superfícies de acondicionamento dos alimentos para venda. Na realidade, panos de limpeza representam uma importante fonte de microrganismos, podendo conter até $10^{8}$ bactérias $/ \mathrm{cm}^{2}$, as quais podem ser transferidas para as mãos ou superfícies limpas em número suficiente para causar infecção se o alimento entrar em contato com estas ${ }^{24}$. Além disso, as condições de umidade que prevalecem nos panos de limpeza favorecem a permanência de altas populações bacterianas, e se estes panos forem usados para secar mãos limpas, podem, em última análise, recontaminá-las ${ }^{25}$.

\section{Análises microbiológicas das superfícies em contato com alimentos comercializados}

As contagens de microrganismos aeróbios mesófilos nas superfícies de acondicionamento dos alimentos variaram de $<1,0 \times 10^{0}$ a $4,2 \times 10^{4}$ $\mathrm{UFC} / \mathrm{cm}^{2}$ (Tabela 2). De acordo com Silva Júnior $^{26}$, as superfícies que entram em contato com alimentos devem conter no máximo 5,0 x $10^{1} \mathrm{UFC} / \mathrm{cm}^{2}$. Considerando este critério, apenas $23,3 \%(7 / 30)$ das superfícies analisadas estavam em condições satisfatórias de limpeza.

Estudo realizado na cidade de Pelotas-RS investigou a qualidade higiênico-sanitária de 60 estabelecimentos ambulantes 5 . A contagem de aeróbios mesófilas nas superfícies de manuseio apontou índice insatisfatório de contaminação em $70 \%$ das amostras, considerando também o critério adotado por Silva Júnior ${ }^{26}$. Assim, esse resultado é semelhante ao encontrado no presente estudo $(76,7 \%-23 / 30)$.

A contagem de microrganismos aeróbios mesófilos não é um indicador de segurança, pois não está diretamente relacionado à presença de patógenos ou toxinas. Porém, é um indicador útil de qualidade porque populações altas desses microrganismos podem indicar deficiências nos procedimentos de limpeza e sanitização ${ }^{27}$.

Embora a porcentagem de superfícies em contato com alimentos apresentando contaminação de aeróbios mesófilos acima do limite recomendado por Silva Júnior ${ }^{26}$ tenha sido muito alta $(76,7 \%)$, o resultado não é surpreendente, visto que a maioria das superfícies não apresentava características adequadas (material resistente à corrosão, tamanho e forma que permitem fácil higienização), não era higienizada satisfatoriamente (água corrente, detergente neutro e posterior sanitização com álcool 70\%) e ainda eram utilizados panos no processo de limpeza dessas superfícies. Assim, os resultados das análises microbiológicas corroboram os dados oriundos do questionário mostrando deficiências das condições de higiene.

\section{Análises microbiológicas das mãos dos vendedores ambulantes}

Os resultados da análise de coliformes (termossensíveis e termotolerantes) e SCP nas mãos dos manipuladores de alimentos dos estabelecimentos ambulantes estão representados na Tabela 2 .

Embora não existam padrões oficiais na legislação brasileira em relação aos manipuladores de alimentos, Silva Júnior ${ }^{26}$ destaca que resultados microbiológicos satisfatórios para a higiene das mãos são ausência de coliformes termotolerantes e contagem de SCP até $100 \mathrm{UFC} / \mathrm{cm}^{2}$ para a coleta com swab nas duas mãos. Em relação a estes critérios, é importante enfatizar que analisamos apenas uma das mãos (mão direita), o que significa que nossos resultados podem estar subestimados. Mesmo com tal ressalva, constatase que o nível de contaminação foi insatisfatório em aproximadamente $47 \%$ dos manipuladores (14/30). Apenas um destes manipuladores (do ponto de venda 19) apresentou contaminação simultânea por coliformes termotolerantes e SCP. Analisando somente os coliformes termotolerantes, resultados insatisfatórios para a higiene das mãos foram verificados em $20 \%$ dos manipula- 
Tabela 2. Análise microbiológica de superfícies em contato com os alimentos e mãos de manipuladores de estabelecimentos ambulantes de Uberaba-MG, entre Novembro de 2012 e Janeiro de 2013.

\begin{tabular}{|c|c|c|c|c|}
\hline \multirow{2}{*}{$\begin{array}{c}\text { Pontos } \\
\text { de venda }\end{array}$} & \multirow{2}{*}{$\begin{array}{c}\text { Superfícies } \\
\text { Microrganismos } \\
\text { aeróbios mesófilos } \\
\left(\mathrm{UFC} / \mathrm{cm}^{2}\right)\end{array}$} & \multicolumn{3}{|c|}{ Mãos dos manipuladores } \\
\hline & & $\begin{array}{c}\text { Coliformes } \\
\text { termossensíveis } \\
(\mathrm{NMP} / \mathrm{mão})\end{array}$ & $\begin{array}{c}\text { Coliformes } \\
\text { termotolerantes } \\
\text { (NMP/mão) }\end{array}$ & $\begin{array}{l}\text { Staphylococcus } \\
\text { coagulase positiva } \\
\text { (UFC/mão) }\end{array}$ \\
\hline 01 & $6,0 \times 10^{1}$ & $<3$ & $<3$ & $<1,0 \times 10^{2}$ \\
\hline 02 & $1,7 \times 10^{3}$ & $<3$ & $<3$ & $<1,0 \times 10^{2}$ \\
\hline 03 & $1,4 \times 10^{1}$ & $<3$ & $<3$ & $<1,0 \times 10^{2}$ \\
\hline 04 & $1,2 \times 10^{1}$ & 1100 & 43 & $<1,0 \times 10^{2}$ \\
\hline 05 & $6,8 \times 10^{2}$ & 3,6 & $<3$ & $<1,0 \times 10^{2}$ \\
\hline 06 & $3,6 \times 10^{1}$ & $<3$ & $<3$ & $2,8 \times 10^{4}$ \\
\hline 07 & $4,2 \times 10^{1}$ & 460 & $<3$ & $<1,0 \times 10^{2}$ \\
\hline 08 & $4,6 \times 10^{2}$ & 15 & 9,2 & $<1,0 \times 10^{2}$ \\
\hline 09 & $6,4 \times 10^{3}$ & $<3$ & $<3$ & $4,4 \times 10^{3}$ \\
\hline 10 & $4,0 \times 100$ & 23 & 9,2 & $<1,0 \times 10^{2}$ \\
\hline 11 & $1,4 \times 10^{2}$ & $<3$ & $<3$ & $<1,0 \times 10^{2}$ \\
\hline 12 & $1,6 \times 10^{2}$ & $<3$ & $<3$ & $<1,0 \times 10^{2}$ \\
\hline 13 & $2,0 \times 10^{2}$ & $<3$ & $<3$ & $<1,0 \times 10^{2}$ \\
\hline 14 & $5,0 \times 10^{2}$ & $<3$ & $<3$ & $<1,0 \times 10^{2}$ \\
\hline 15 & $1,0 \times 104$ & 150 & $<3$ & $<1,0 \times 10^{2}$ \\
\hline 16 & $8,0 \times 10^{1}$ & 21 & $<3$ & $<1,0 \times 10^{2}$ \\
\hline 17 & $2,0 \times 101$ & $<3$ & $<3$ & $<1,0 \times 10^{2}$ \\
\hline 18 & $4,2 \times 104$ & $>1100$ & $<3$ & $<1,0 \times 10^{2}$ \\
\hline 19 & $4,4 \times 10^{3}$ & $>1100$ & 460 & $5,2 \times 10^{4}$ \\
\hline 20 & $<1,0 \times 10^{0}$ & $>1100$ & 11 & $<1,0 \times 10^{2}$ \\
\hline 21 & $2,0 \times 10^{3}$ & $>1100$ & $<3$ & $<1,0 \times 10^{2}$ \\
\hline 22 & $1,0 \times 10^{3}$ & $>1100$ & $<3$ & $<1,0 \times 10^{2}$ \\
\hline 23 & $5,6 \times 10^{3}$ & $<3$ & $<3$ & $2,0 \times 10^{4}$ \\
\hline 24 & $9,6 \times 10^{2}$ & $<3$ & $<3$ & $<1,0 \times 10^{2}$ \\
\hline 25 & $1,8 \times 10^{2}$ & $<3$ & $<3$ & $2,8 \times 10^{6}$ \\
\hline 26 & $5,8 \times 10^{2}$ & 150 & 9,2 & $<1,0 \times 10^{2}$ \\
\hline 27 & $1,1 \times 10^{3}$ & $<3$ & $<3$ & $4,4 \times 10^{4}$ \\
\hline 28 & $6,6 \times 10^{2}$ & 240 & $<3$ & $2,9 \times 10^{4}$ \\
\hline 29 & $6,0 \times 10^{2}$ & $<3$ & $<3$ & $8,6 \times 10^{3}$ \\
\hline 30 & $2,2 \times 10^{2}$ & $<3$ & $<3$ & $1,1 \times 10^{4}$ \\
\hline
\end{tabular}

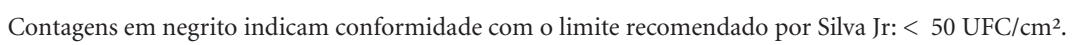

dores (6/30). Para os SCP, o nível de insatisfação alcançou 30\% (9/30).

Os coliformes termossensíveis, embora tenham sido incluídos em nosso estudo, não são estudados nas análises convencionais, por não serem bons indicadores de contaminação, aparecendo mesmo após a higiene das mãos ${ }^{26}$. Dessa forma, não foi possível determinar o significado dos nossos resultados para estes microrganismos.

Staphylococcus coagulase positiva é altamente sensível ao calor e a agentes sanitizantes; portanto, sua presença nas mãos pode indicar higiene pessoal deficiente e, consequentemente, maior risco de contaminação dos alimentos manipulados ${ }^{28}$. Da mesma forma, como os coliformes termotole- rantes não fazem parte da microbiota normal residente da pele, sua presença nas mãos caracteriza uma situação de risco potencial, devido à inter-relação destas bactérias com a possível ocorrência de patógenos entéricos ${ }^{21}$. Em outras palavras, a detecção de coliformes termotolerantes nas mãos sugere contaminação fecal, indicando fortemente que o processo de higienização foi deficiente e, consequentemente, que as mãos analisadas podem ser fonte de contaminação dos alimentos ${ }^{29}$.

A lavagem das mãos, apesar de ser uma forma simples e eficaz para reduzir a contaminação cruzada, é muitas vezes esquecida. Foi relatado que $42 \%$ dos surtos de doença transmitidas por alimentos que ocorreram entre 1975-1998 nos 
Estados Unidos foram causados pelas mãos dos manipuladores de alimentos ${ }^{9}$.

Em relação a vendedores ambulantes, a questão da lavagem das mãos é ainda mais crítica, pois na maioria das vezes o estabelecimento ambulante não possui infraestrutura básica adequada para esta prática, tais como água corrente potável, pia, sabão e toalha de papel descartável ${ }^{3}$.

Além da falta de infraestrutura adequada, outras irregularidades detectadas durante a aplicação do questionário para avaliação das condições higiênico-sanitárias podem explicar a alta porcentagem, encontrada no presente trabalho, de mãos de vendedores ambulantes com condições microbiológicas insatisfatórias para a manipulação de alimentos. Dentre estas irregularidades podemos destacar: baixa adequação dos ambulantes em relação a itens associados à higiene pessoal (Tabela 1), manipulação de dinheiro e alimentos simultaneamente, falta de lixeiras com acionamento não manual das tampas, falta de utilização de antissépticos para as mãos, secagem das mãos com panos. Em relação a este último item, Clayton e Griffith ${ }^{30}$ destacam que a secagem das mãos é um ponto crítico no processo de lavagem das mãos e importante para reduzir a transmissão de patógenos, uma vez que a umidade residual pode aumentar a transferência de qualquer microrganismo restante presente nas mãos para as outras superfícies. No entanto, o uso de panos para esta finalidade não é adequado, pois o pano representa uma fonte de contaminação considerável ${ }^{30}$.

É importante ressaltar que as amostras para a realização das análises microbiológicas foram coletadas de mãos consideradas higienizadas por parte dos manipuladores. Segundo Silva Júnior ${ }^{26}$, coliformes termotolerantes e SCP são considerados importantes indicadores de contaminação e de condutas inadequadas de manipulação, sendo os resultados válidos como monitoramento do processo de higiene apenas quando as amostras são colhidas após a higiene das mãos.

\section{Conclusão}

A avaliação dos comércios ambulantes de alimentos revelou condições higiênico-sanitárias insatisfatórias e risco de contaminação dos alimentos disponíveis para venda.

Os riscos para a saúde do consumidor poderiam ser minimizados pela adoção de práticas adequadas de manipulação de alimentos, incluindo a correta higienização de mãos e superfícies. De modo geral, constatou-se a necessidade de aumentar o nível de conhecimento dos manipuladores de alimentos sobre segurança alimentar, englobando fatores de higiene pessoal e cuidados na preparação e armazenamento dos alimentos de rua.

Diante de tais achados, considera-se de extrema importância a adoção de programas de treinamento eficazes e permanentes em segurança alimentar para os vendedores ambulantes de alimentos da cidade de Uberaba-MG, além do aumento do rigor no cumprimento dos requisitos necessários para o registro de funcionamento e a intensificação do processo de fiscalização.

\section{Colaboradores}

GC Souza trabalhou em todas as etapas da pesquisa e redação final como orientanda, L Alves e AA Andrade na pesquisa, redação final e orientação geral, CTB Santos na coleta e análise microbiológica. 


\section{Referências}

1. Germano MIS, Germano PML, Kamei CAK, Abreu CS, Ribeiro ER, Silva KC, Lamardo LCA, Rocha MFG, Vieira VKI, Kawasaki VM. Manipuladores de alimentos: capacitar? É preciso. Regulamentar? Será preciso? Hig aliment 2000; 14 (78/79):18-22.

2. Feglo P, Sakyi K. Bacterial contamination of street vending food in Kumasi, Ghana. J Med Biomed Sci 2012; 1(1):1-8.

3. Lues JF, Rasephei MR, Venter P, Theron MM. Assessing food safety and associated food handling practices in street food vending. Int J Environ Health Res 2006; 16(5):319-328.

4. Muyanja C, Nayiga L, Brenda N. Nasinyama G. Practices, knowledge and risk factors of street food vendors in Uganda. Food Control 2011; 22(10):1551-1558.

5. Rodrigues KL, Gomes JP, Conceição RCS, Brod CS, Carvalhal JB, Aleixo JAG. Condições higiênico sanitárias no comércio ambulante de alimentos em Pelotas -RS. Ciên Tecnol Aliment 2003; 23(3):447-452.

6. Furlaneto AF, Kataoka A. Análise microbiológica de lanches comercializados em carrinhos de ambulantes. Lecta 2004; 22(1/2):49-52.

7. Omemu AM, Aderoju ST. Food safety knowledge and practices of street food vendors in the city of Abeokuta, Nigeria. Food Control 2008; 19(4):396-402.

8. Mensah P, Yeboah-Manu D, Owusu-Darko K, Ablordey A. Street foods in Accra, Ghana: how safe are they? Bull World Health Organ 2002; 80(7):546-554.

9. Lues JF, Van Tonder I. The occurrence of indicator bacteria on hands and aprons of food handlers in the delicatessen sections of a retail group. Food Control 2007; 18(4):326-332.

10. Cosby CM, Costello CA, Morris WC, Haughton B, Devereaux MJ, Harte F, Davidson PM. Microbiological Analysis of Food Contact Surfaces in Child Care Centers. Appl Environ Microbiol 2008; 74(22):6918-6922.

11. Coelho AI, Milagres RC, Martins JF, Azeredo RM, Santana AM. Contaminação microbiológica de ambientes e de superfícies em restaurantes comerciais. Cien Saude Colet 2010; 15(Supl. 1):1597-1606.

12. Andrade NJ, Silva RM, Brabes KC. Avaliação das condições microbiológicas em unidades de alimentação e nutrição. Cienc agrotec 2003; 27(3):590-596.

13. Fawzi M, Gomaa NF, Bakr WM. Assessment of Hand Washing Facilities, Personal Hygiene and the Bacteriological Quality of Hand Washes in Some Grocery and Dairy Shops in Alexandria, Egypt. J Egypt Public Health Assoc 2009; 84(1,2):71-93.

14. Agência Nacional de Vigilância Sanitária (Anvisa). Resolução - RDC no. 216, de 15 de setembro de 2004. Dispõe sobre regulamento Técnico de Boas Praticas para Serviços de Alimentação. Diário Oficial da União 2004; 15 set.

15. American Public Health Association (APHA). Compendium of Methods for the Microbiological Examination of Foods. $4^{\text {th }}$ ed. Washington: American Public Health Association; 2001.

16. Oliveira MN, Brasil ALD, Taddei JAAC. Avaliação das condições higiênico sanitárias das cozinhas de creches públicas e filantrópicas. Cien Saude Colet 2008; 13(3):1051-1060.

17. Siqueira RS. Manual de microbiologia de alimentos. Brasília: EMBRAPA-SPI; 1995; p. 159.
18. Muinde OK, Kuria E. Hygienic and Sanitary practices of vendors of street foods in Nairobi, Kenya. Afr J Food Agric Nutr Dev 2005; 5(1):1-14.

19. Nonato IL, Fonseca VRS, Paz JG, Nomelini QSS, Pascoal GB, Souza DAD. Qualidade higiênico sanitária de pontos de venda e análise microbiológica de alimentos de rua comercializados no campus Umuarama da universidade federal de Uberlândia. Biosci J 2012; 28(6):1061-1071.

20. Chukuezi CO. Food Safety and Hyienic Practices of Street Food Vendors in Owerri, Nigeria. Stud Sociol Sci 2010; 1(1):50-57.

21. Campos AKC, Cardonha MAS, Pinheiro LBG, Ferreira NR, Azevedo PRM, Stamford TLM. Assessment of personal hygiene and practices of food handlers in municipal public schools of Natal, Brazil. Food Control 2009; 20(9):807-810.

22. Lucca A, Torres EAFS. Condições de higiene de "cachorro-quente" comercializado em vias públicas. Rev Saude Pub 2003; 36(3):350-352.

23. Associação Brasileira de Refeições Coletivas (ABERC). Manual ABERC de Práticas de Elaboração e Serviço de Refeições para Coletividades. 9a ed. São Paulo: ABERC; 2009.

24. Rusin P, Orosz-Coughlin P, Gerba C. Reduction of faecal coliform, coliform and heterotrophic plate count bacteria in the household kitchen and bathroom by disinfections with hypochlorite cleaners. J Appl Microbio 1998; 85(5):819-828.

25. Meredith L, Lewis R, Haslum M. Contributory factors to the spread of contamination in a model kitchen. Brit Food J 2001; 103(1):23-35.

26. Silva Júnior EA. Manual de controle higiênico sanitário em alimentos. São Paulo: Varela; 2008.

27. Silva N, Junqueira V, Silveira NFA, Taniwaki MH, Santos RFS, Gomes RAR. Manual de métodos de análise microbiológica de alimentos e água. $4^{\text {a }}$ ed. São Paulo: Varela; 2010.

28. Dharod JM, Paciello S, Bermúdez-Millán A, Venkitanarayanan K, Damio G, Pérez-Escamilla R. Bacterial Contamination of Hands Increases Risk of Crosscontamination among Low-income Puerto Rican Meal Preparers. J Nutr Educ Behav 2009; 41(6):389-397.

29. Millezi AF, Hoffmeister S, Kayzer VL, Tonial TM. Microbiological quality of the hands of food handlers and of the sanitizer in the meat processing industry. Arq Cienc Saude UNIPAR 2011; 15(2);135-139.

30. Clayton DA, Griffith CJ. Observation of food safety practices in catering using notational analysis. Brit Food J 2004; 106(3):211-227.

Artigo apresentado em 26/09/14

Aprovado em 13/03/15

Versão final apresentada em 15/03/15 